\section{A NEW CAMERA LUCTDA}

THE various kinds of camera lucida hitherto used have always possessed many inconveniences, none of them allowing to be seen upon the paper with sufficient precision, and simultaneously, the image of the object and the point of the pencil. For the purpose

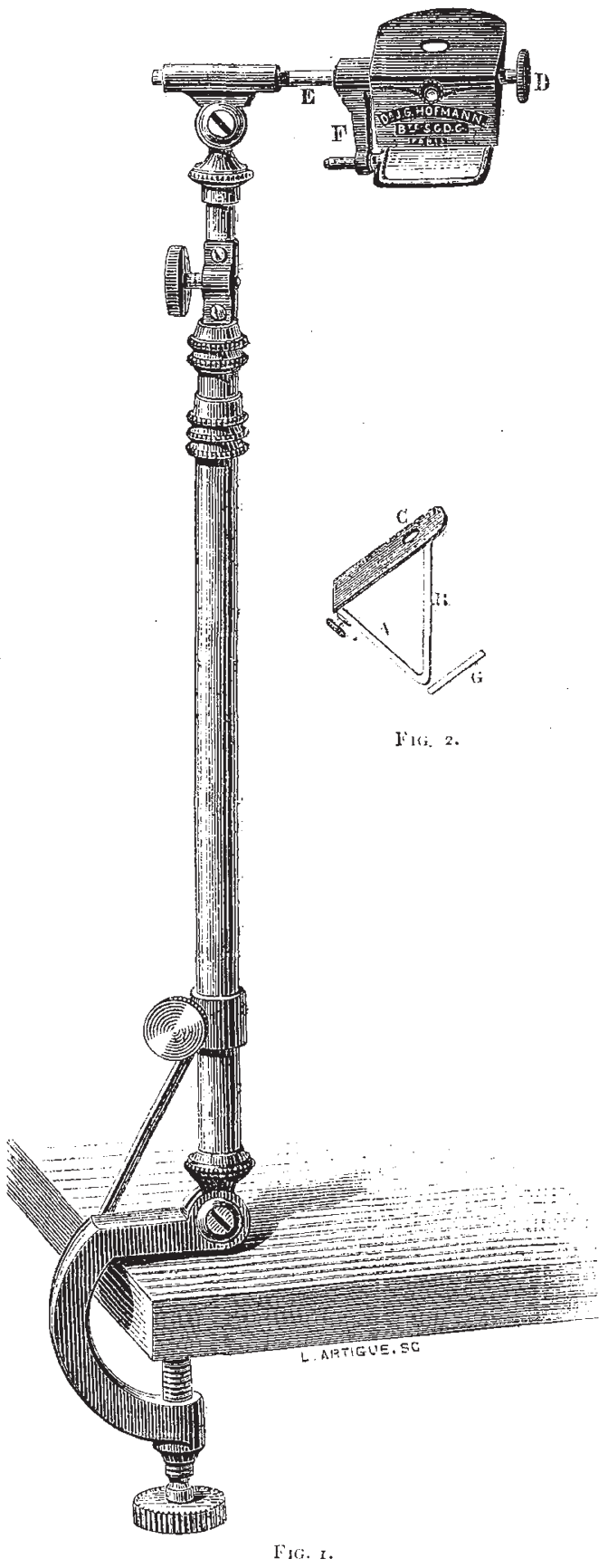

of remedying this inconvenience, Dr. J. G. Hofmann, of the Rue Bertrand, Paris, has had recourse to an arrangement by which he believes he has obtained the most satisfactory results. The illustration will give some idea of this arrangement.

Fig. I represents the general elevation, in half size, of Hofmann's camera lucida. Fig. 2 is a transverse section of the optical part, composed, at $\mathrm{A}$, of a metallised mirror, or other metallic surface, polished and rigorously plane; at $\mathrm{B}$, of a small plane mirror of parallel glass, forming, with the metallised mirror, a fixed angle. The function of the latter is to let pass a part of the luminous rays coming from the object to be drawn, and to show at the same time the point of the pencil alongside the image upon the paper. At $G$ may be placed, in a movable frame, either a plate with parallel surfaces, or lenses of neutral glass of various foci, the principal object of which is to enable a satisfactory drawing to be made of the objects placed inside, when using white paper; for the outside, this glass serves to temper the brightness of the sun.

At $\mathrm{C}$ is the eye-hole or opening before which the eye is placed. The knob $D$ serves to place the chamber in a convenient position, which sometimes depends on that of the artist with respect to the object; but generally it is convenient to place the mirror $D$ vertically. With the same pieces of the optical part, with the addition of a concentrating lens, Dr. Hofmann has been able to construct a second model applicable to microscopes, for which, as well as for telescopes, all previous forms of camera have given only very mediocre results.

\section{ANATOMICAL PREPARATIONS FOR MUSEUM} AND CLASS PURPOSES

I $\mathrm{N}$ a former number of NATURE (vol. xvi. p. 360) I offered some suggestions on museum preparations and arrangement. These I can now supplement by a new method which I have tried with encouraging success.

No museum-curator needs to be reminded of the many defects of the ordinary fluid-preservatives. Evaporation, blanching, spilling, optical distortion, the cost and inconvenient shape of glass vessels-these are among the serious and apparently inevitable advantages of dilute spirit. I have found it possible to get rid of all these difficulties together by mounting dissections and entire animals in glycerine jelly.

The following directions may be followed until experience shall suggest better. Soak gelatine (best quality) in water until it has absorbed as much as it can, melt and add an equal bulk of best German glycerine. Clarify with white of egg, one egg to a pint of mixture, taking care to boil very steadily, without burning. Filter hot through flannel. The jelly should be transparent, and of a pale straw-colour. It should melt at $39^{\circ} \mathrm{C}$., and have a specific gravity of $x \cdot 186$ at $8^{\circ} \mathrm{C}$., compared with water at the same temperature.

The jelly may be diluted with water, with glycerine, or with a mixture of the two. I find one part of jelly to one of glycerine and one of water a convenient proportion. The dilute jelly is apt to run fluid on exposure to the air, owing to the growth of moulds. This may be prevented by using a solution of salicylic acid or thymol in water for dilution. These substances cause opalescence in the medium, but a very minute quantity of acetic acid clears it again.

Lay out the dissection on wax, as recommended in my previous letter, but without pins, and fill up with jelly rendered fluid by gentle heat. When the vessel is full, allow the jelly to cool and set, then pour a little more on the top. After this also has set, lay the glass cover (warmed by immersion in hot water) in its place. As the superficial layer of jelly melts, press the cover down. When cold, cement the edges with strips of cloth smeared with coaguline.

The vessel for mounting may be of almost any size and shape. I have tried glass jars, built-up glass cells, ebonite, gutta percha, earthenware, and wood soaked in paraffin. The vessel should be strong and quite air-tight.

It is early as yet to speak of the final result. Some preparations have lasted five months without alteration. 
The inert character of glycerine jelly, so well-known to microscopic mounters, justifies confidence in its stability. A large proportion of glycerine may render certain objects too transparent. This tendency may be corrected by changing the proportions as required, or by adding alum. I have found even delicate colours, such as those of squids, readily preserved by the jelly. No effusion of mucus or colouring matter takes place, and an animal may be mounted fresh if care be taken that the jelly penetrates sufficiently into cavities of the body. Previous immersion in alcohol, or other preservatives, does not prevent re-mounting in glycerine jelly. Many of the srdinary reagents used by the histologist may be added to obtain special results. I have not as yet succeeded with large objects, but mountings with as much as a pint of jelly have done well.

The cost of the jelly is not prohibitive, and when the freedom from loss by evaporation, or spoiling by turbidity and discoloration is considered, this mode of preparation will be found cheapest in the end. Harvey and Reynolds, of Leeds, undertake to supply the undilute jelly at a moderate price.

Until experience suggests improvements I have nothing to add. The preparations ought to be kept for years before the new process can be recommended in unqualified terms. I think, nevertheless, that I have already seen enough to warrant the anticipation that mounting in jelly will for certain purposes displace all the fluid methods in use.

L. C. Miall

Leeds Museum

\section{$B E E S$}

$A \mathrm{~N}$ American correspondent writes asking Mr. A. R. A Wallace, through NATURE, his opinion as to the genus Apis. Are dorsata, zonata, indica, adansoni, nigro. cincta, and florea, each or all distinct species? or, our correspondent asks, are some of these like ligustica and fasciata, simply varieties of mellifica? Also as to structure and habits of $A$. dorsata and others, which $\mathrm{Mr}$. Wallace has personally seen and handled.

The following reply has been sent us to these queries :-

Mr. Alfred R. Wallace having suggested that I should answer the queries of your American correspondent, I do so at once, having in the year. 1865 published in the Annals and Magazine of Natural History, a somewhat elaborate paper on the subject on which information is sought for. The species that in my opinion are distinct are Apis mellifica, A. adnnsoni, A. dorsata, A. zonata, $A$. unicolor, $A$. indica, and $A$. florea. I do not consider the examination of worker bees only sufficient material to enable any one to form a decisive opinion as to species ; the examination of drones, also, I consider indispensable ; it is advantageous to see queens, but those which $I$ have seen do not present any very marked peculiarities indicative of specific distinction. I possess males and workers of $A$. dor sata, $A$.indica, and $A$. florea. That $A$. ligustica and $A$. fasciata are climatal varieties of $A$. inellifica has been apparently proved by the fact of their having in England reverted to the original stock, $A$. mellifica; there is, however, a remarkable fact to be noticed that, notwithstanding the change referred to, they still possess a much greater degree of irascibility than $A$. mellifica; $A$. fasciata undoubtedly in the greatest degree. I consider $A$. zonata distinct from $A$. dorsata, its nearest ally ; it is a larger bee, jet-black, with snow. white bands on the abdomen; I have not seen $A$. dorsata from Celebes, where $A$. zonala was discovered by Mr. Wallace, but he found that species in Sumatra, Flores, Timor, and Gilolo. $A$. adansoni, and $A$. nigro-cincta, will probably prove to be climatal varieties of one species, the latter being a pale form with dark bands. There is no doubt of $A$. indica being a distinct species, all the sexes are known, and there is no other species found in India with which it could be assimilated. Of the specific distinction of $A$. florea, the remarkable structural formation found in the drone, that of a lobe on the metatarsus, is conclusive; it is also much the smallest species known of the genus Apis. A. unicolor inhabits Madagascar, Mauritius, and the Island of Rodriguez; a considerable portion of a swarm was obtained from the latter island, an examination of which inclines me to consider the insect much more than a climatal variety of any other species; it remains that the drones and queens should be obtained in order to decide the question; until this can be effected I shall consider $A$. unicolor a good species.

Of the habits of the species of the grenus Apis, Mr. Wallace, Sir John Hearsey, Dr. Jerdon, and Mr. Chas. Horne have given some interesting particulars. A. dorsato suspends its mass of combs on the branches of trees, quite exposed, having no covering whatever; Sir John Hearsey succeeded in obtaining a swarm which he secured in a box-hive, thus domesticating the species, and obtaining from time to time quantities of delicious honey. Dr. Jerdon gave me combs of $A$. indica, which had taken up its abode in the rafters of an outhouse. Mr. Horne gave me the comb of $A$. florea; it is attached to a twig of some bushy plant. Dr. Welwitsch brought combs of $A$. adansoni from Angola ; they were found inside a hollow tree; the cells are considerably smaller than those of any of the honey-bees of Europe.

FREDERICK SIITH

British Museum

\section{THE ORION NEBULA}

A SHORT time ago we gave an abstract of d'Arrest's A "spectroscopical researches." The Danish paper contains also the conclusions at which he arrived after many years contemplation of the nebula in the swordhandle of Orion. The spectrum is now easily visible, with open slit, even without a telescope. Then we see three images of the nebula corresponding to the three lines, whose relative intensity d'Arrest found to be 100,24 , and 7I. To see the fourth line is of course very difficult. If the spectrum of the stars is looked at together with that of the nebula, we find the nebular lines continue absolutely unimpaired through the inner trapeze. Consequently it cannot be considered as proved that the stars are in connection with the nebula. It has not, of course, yet been possible to ascertain spectroscopically whether the stars are nearer to us than the nebula, or farther away in space. The question of resolvability has lost a good deal in interest since Huggins showed its gaseous nature. However, d'Arrest would not believe that it had ever been resolved into stars in any of the large telescopes of his day. All the more startling was the Rev. Dr. Robinson's letter (NATURE, vol. xv. p. 292), that he as early as 1848 had resolved this nebula with the Earl of Rosse's telescopes. It would be worth while for Mr. Ellery, who, according to our astronomical column, is investigating the southern nebula, to ascertain whether actual resolvability is referred to here, or the circumstance that, as might be expected in so enormous a reflector, a good many small stars become visible by glimpses. Liapounov describes the appearance of Regio Hugeniana as follows : "Ces masses m'avaient présenté a plusieurs occasions des ressemblances frappantes avec des amas d'etoiles. Le caractère stellaire s'est prononcé d'abord dans la masse la plus lumineuse, dont l'apparence me conduisait depuis constamment à l'idée d'une agglomération de petites étoiles condensées." . We are hardly right in concluding that the nebula could be resolved in the nine-inch refractor of the Cazan observatory.

The Orion nebula was first pictured together with the four stars of the trapeze by Huyghens, who discovered it in 1656 , though Cysat referred to it already in 1618 . It was afterwards examined by Derham, Godin, Fouchy, Mairan 